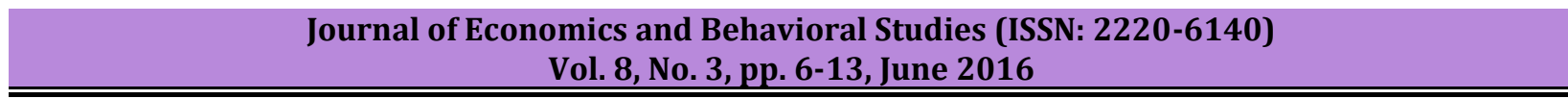

\title{
Role of Communication in Developing Psychological Contract Breach: Mediating Role of Power Distance
}

\author{
Marvi Mallah, Sumaiya Syed, Salman Bashir Memon \\ Shah Abdul Latif University, Khairpur Mirs, Pakistan \\ ssm_syed@yahoo.com
}

\begin{abstract}
The communication plays very important role across organizations. Similarly, the psychological contract exists all the time within the organization. This article explains the role of communication in minimizing the psychological contract breach (PCB) mediated by power distance. The organizations are required effective communication in order to create a strong bond between the organization and the employees. The PCB not only has harmful impact on employees but also negatively affect the performance of the organization. This research suggests the impact of communication on PCB if the communication is strong there are more chances of low PCB but if communication is not strong the chances of high PCB within the organization is observed. The research also examines the communication mediated by high and low PD and suggests its impact on the PCB. The research suggest within the organization if communication is strong its leads toward the lower PCB among the employees and when the communication is mediated by lower power distance it will leads toward the lower PCB vis-a-vis.
\end{abstract}

Keywords: Communication, Psychological Contract Breach (PCB) and Power Distance (PD), Pakistan

\section{Introduction}

The concept of psychological contract with its focuses on exchange promises and obligations is increasingly used to understand employment relationship .Psychological contract PC refers to beliefs that people hold regarding promises that others make with them (Guest, 1998). In organizations, these contracts include employers' and employees' expectations to each other (Bambacas \& Patrickson, 2008). PCB refers to the employee's perception of the extent to which the employer has failed to fulfill any or all of the obligations owed to the employee (Morrison \& Robinson, 1997). More specifically, PCB is the "cognition that one's organization has failed to meet one or more obligations within one's psychological contract in a manner commensurate with one's contributions" (Morrison \& Robinson, 1997, p.230). The communication plays an important role in developing the PC in the internal promotion of employees as it is an important factor that elicits the employee beliefs, feelings, perceptions (Bambacas \& Patrickson, 2008) and eventually determines the value addition of their service-providing motivation to the entity; this almost in turns arise as human capital(Thomson \& Hecker, 2001).

The communication literature categorizes communication' into two broader categories: i) formal and ii) informal (Bambacas \& Patrickson, 2008). In case of formal communication, there is established set of rules through which information discriminates vertically and horizontally. However, in case of an informal communication, the information flows along the informal network of communication. During the hiring process, the employer and interviewee communicate what they can offer in the prospective relationship (Hiltrop, 1996). After the appointment they also communicate in order to assign responsibilities. Instead, during their work in the offices, people communicate in daily activities. The effective communication skills (Bambacas \& Patrickson, 2008) strengthen interaction arena in an organization among working employees. Some studies also determine that power distance helps in effective communication and maintaining the PC development (Guest, 2004). Power distance refers to the degree to which less powerful members of a society expect and accept the unequal distribution of power (Hofstede \& Bond, 1984). Hofstede Dimensions of Culture Pakistan is high power distance (Latif, 2015) with the score of 55, this might influence on exchange process of employment relationship. Despite this, past research on psychological contracts has focused on certain core areas of the exchange relationship, and has neglected a diverse range of other possible aspects of communication. More specifically the research in Pakistan is dearth in the literature in context of psychological contract breach, communication and power distance 


\section{Communication and Its Significance}

Generally, communication is a process of sharing information, ideas and messages with colleagues and natives working or living around in a specific place (Dessler, 2013). It includes inscription and conversation, as well as, non-verbal contact (e.g. facial expressions, body language, and gestures), visual contact (the usage of images, such as paintings, photography, or videos), and electronic contact i-e. Telephonic, e-mail, or satellite broadcasting (Dessler, 2013). It is a most important part of individual lives that holds a multiple role and impact in the business practices, education, and any other state of affairs where inhabitants encounter each other and develop PC (Hiltrop, 1996). Communication is most vital and fundamental element in the management process (Hiltrop, 1996), as it is based on working with people; it is a reflective strategy in business as blood stream of administrative organization or management heart. Thomson \& Hecker (2001) stated this as an 'internal branding' for an entity. It has deeply gotten undeniable position in modern-day organizational setting. Communication is the exchange of information and transmission of meaning and that is very essence of an organization (Khan, 2008-2009).

The communication forms of cognition are different within the organization, like initial entry, day to day work and more future oriented top down communication (Guzzo \& Noonan, 1994). Most of the organizations, in Pakistan are information centric thus the key of this research would incline the formal and vertical (top-to-down or down-to-top) communication as it more of the value to focus on task and role related communication to ensure the outcomes of research study and signify the relationship of each dimension that may consider innumerable skills at the same time (Bambacas \& Patrickson, 2008). Besides this, some of the studies suggest that if different forms of communication are used effectively within the organization it will have obvious results in promoting the values (Clutterbuck, 2005), of psychological contract that will ultimate trigger he employment force to job commitment and job satisfaction (Bambacas \& Patrickson, 2008), and will less frequently used to breach of PC (Gust, Conway, 2002; Gust, 2004).

Psychological Contract: Psychological contract is a set of 'promises' or 'expectations' that are exchanged in between two parties (Guest, 2004). These parties include employers, employees and their work colleagues. It is the trust (Guest, 2004), that two parties hold for each other to fulfill the promises as it forms a basis of commitments (Jacobs, 2006) within the organization. In modern practices, PC is defined in between the two nodes i.e. the link to provide discrete function ideology of giving and taking in relation to commitments (Sparrow \& Cooper, 2003). It also includes the simple definition of Herriot as the perception of two for what their shared requirements are to each other. A PC is a shared agreement of responsibility in support to specified terms and conditions (Guest, 2004). In other words, PC is a parameter of employment relations (Coyle-Shapiro \& Conwey, 2006) of promises and commitments must have a clearer sense of communicating the obligations of both parties (Guest \& Conway, 2002). PC can also be described as a' transactional contracts' and 'relational contracts'. The transactional PC is economic based in which employees expect that the organization will fairly compensate their performance delivered and punish inadequate or inappropriate acts. However, the relational PC is a socio-emotional based in which expectations of shared ideals, values, and respect (Clutterbuck, 2005) thereby support in the interpersonal relationships (David \& Thomas, 2003). Maintaining the PC is an important part of positive employee relation. PC requires interaction and communication (Clutterbuck, 2005) between the two parties. Over time, a climate of trust is developed if both parties are continuously fair in their actions, keep their explicit and implicit promises, and maintain commitment. It is, especially important for management to be consistently fair and communicate what so ever is perceived time by time.

Relationship between Effective Communication and Psychological Contract Breach: Organizations are concerned to communication (Guzzo \& Noonan, 1994) in numerous exceptional ways. Some builds and put in contact tools such as, e-mail, fax, personal computers, and telephones; others create some of the communication or content that those technologies transmit, such as orientation movies, manuals, handbooks and learning software, even they can be a part of media or telecommunications. People in organizations require communicating to coordinate their work and its outcomes (Bambacas \& Patrickson, 2008); and to inform to outer surface of the entity about their company products and corporate services (these kinds of communication are called advertising or public relations). PC is having highest relationship with communication (Jacobs, 2006) channel; as communication improves (Bambacas \& Patrickson, 2008) the 
climate of trust by ensuring the interaction of organizational forthcomings to the employees, business partners, customers, its stakes and management (Clutterbuck, 2005).

This literature of psychological contract has draws the attention to three areas of communication. Robinson and Morrison (2000) highlight the importance of communicating the psychological contract during the process of recruitment, while Herriot and Pemberton (1997), and emphasize the importance of ongoing interaction between the employer and the employee in relation to the job and to personal issues such as workload, development, and work-life balance and career prospects. More broadly, Turnley and Feldman (1999) highlight the importance of formal top-down communications, such as mission statements for the psychological contract. All these studies are suggesting that effective organizational communication will lead to a more explicit and potentially more effective psychological contract that might reduce the Psychological contract breach. Most employee studies (e g Turnley and Feldman, 1999; Robinson and Morrison, 2000) lend support to psychological contract violation and psychological contract breach is major explanatory variable for attitudes and behavior. There have, however, been very few studies that have considered antecedents to such contracts. (Wanous et al., 1992) has highlighted the importance of clear communication Furthermore, as Morrison and Robinson (1997) highlight, lack of communication is likely to lead to incongruence between employer and employee perception of obligations is one of the causes of contract breach. In this context, PC breach (Bhargava, 2013) occurs when employees perceive their employer fails to fulfill the promises and obligation and when these promises and commitments are fulfilled by the employer (Guest, 2004) is more likely to stay with the organization and commitment will also increase. Violation of the PC results in the changing behavioral responses of the employees. These behavioral responses are categorizes as exit, voice, loyalty (Hiltrop, 1996) and neglect. Thus, we come to know about the two hypotheses: in relation-1 (R1) as:

H1: Effective communication would lead to lower PCB

H2: Ineffective communication would lead to higher PCB

Power Distance: The influence of culture differences in employment relationship is very important but neglecting area, according to Hofstede \& Bond 1984 power distance is one the cultural dimension. Power distance (PD) is a term that describes how people view power relationships as superior-subordinate relationships. PD also remained part of the cultural dimensions theory (Hofstede, 1973-78, p-23) and can be defined as;"representation of extent to which the less powerful individual members of institutions agree to and look forward to an unequal sharing of power; his other study dimensions include individualism, masculinity, uncertainty avoidance index, long-term orientation". PD can be classified into two categories such as, high PD and low PD. The employees residing in the horizons of high PD will reflect more real life and believe to be having the specific place in organizational power hierarchy. The power distribution in high PD organizations is unequal and people in such type of organizations easily accept the modes of autocratic and paternalism leadership. They feel dependence in decision making (Hiltrop, 1996) and are worried of management involvement; while employees in Low PD expect for power role and holds the strong nodes of democratic and consultative leadership (Bambacas \& Patrickson, 2008) in their organization, they feel independence in decision making and are not worried of management involvement. The in low power distance there is egalitarian relationship between the superior and subordinate. Dutch organizations are very famous for the low power distance organization. Where manager does not make decisions but they make teams and lead them. On the contrary the USA has mild power distance as we would not expect to see our President waiting at an ATM machine on the side of the road. Where as in India culture prefer high power distance organization. In high power distance manager will decide and subordinate will follow (Moore, 2006). With a score of 55 on power distance, Pakistan can be considered a hierarchical society. This means that people accept a hierarchical order in which everybody has a place and which needs no further justification.

Effective Communication and PCB Outcomes: Power Distance as a Mediator: In communication modes, the mediating role of PD is a determinant to successful organizational setting, cultural manifestations (Jacobs, 2006) and PC development. At the organizational point, statement about relationship of PD not only reflect the wider scope of organizational culture (Hiltrop, 1996), but it also differentiated the way through which it can be used and implemented within organizational setting. There are following reasons that indicate that why Power Distance may cause lack of Communication between subordinates and superiors: 1) Communication apprehension - 'Communication apprehension in an individual level of fear or anxiety associated with either real or anticipated communication with another person or persons. 2) Unwillingness to communicate - 'Unwillingness to communicate is a predisposition representing a chronic tendency to avoid 
and/or devalue oral communication.3) Dependency - 'In countries in which employees are not seen as very afraid and bosses as not often autocratic or paternalistic, employees express a preference for a consultative style of decisions making: a boss who, as the questionnaire expressed, "usually consults with subordinates before reaching a decision. Individuals thus need to be communicated time by time and across a distance in the organizational setting that what type of behavior they might display at work, how they may communicate and perceive the betterment of organization and self. More specifically, organizational goal setting (Bambacas \& Patrickson, 2008) is highly critical and subject to outcome differentiation based on what so ever is being communicated to individuals in high or low PD orientation. Thus, we come to know about the two hypotheses relation-2 (R2) as:

H3: Higher PD with effective communication would lead to Higher PCB

H3: Lower PD with Effective communication would lead to Lower PCB

\section{Figure 1: Research Framework}

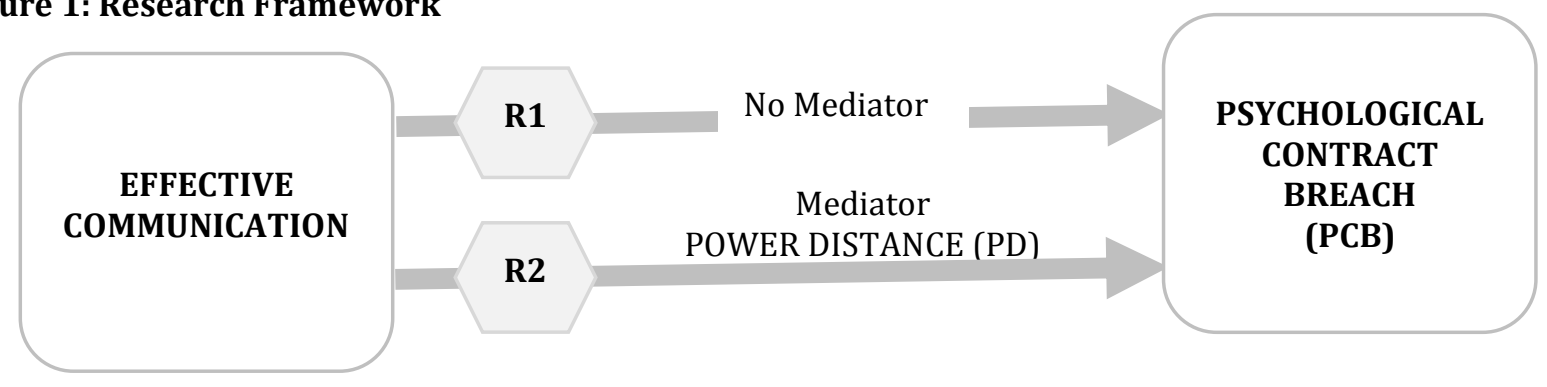

\section{Methodology}

The research is an inclusive study of literature that tries to find the relationship, significance and outcome for the considered variables.

Data Collection Sources: The research uses both primary and secondary sources of data; primary data includes questionnaire for the three variables consisting of effective communication, PC and PD which can be measured by using five point Likert scale; whereas secondary data includes reviewing the diverse periodicals publication of the articles and related book chapters.

Data Sampling: The total number of respondents was 207 and data was collected from community colleges.

Data Analysis Techniques: In case of this study, the researcher employed quantitative data analysis technique. The primary and secondary data sources were used for data collection.

Primary Data: Questionnaire was designed which consisted of four demographics and forty research variables. Questions were based on five point scale:

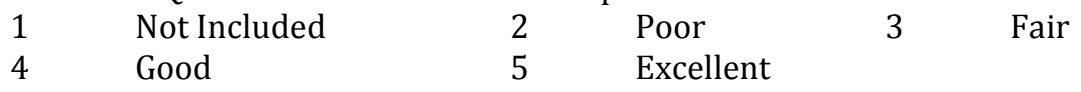

Secondary Data: Relevant and published research papers and research reports were used for quoting the work related to our data.

\section{Hypothesis:}

H1: Effective communication would lead to lower PCB.

H2: Ineffective communication would lead to higher PCB.

H3: Higher PD with effective communication would lead to Higher PCB.

H3: Lower PD with Effective communication would lead to Lower PCB.

\section{Diagnostic Tests}

$$
\mathrm{EC}=\alpha+\mathrm{LPCB} \beta 1+\mathrm{HPCB} \beta 2+\operatorname{LPD} \beta 3+\operatorname{HPD} \beta 4+\mu
$$




\section{Results}

The result of the diagnostic test suggested independent variable EC is positively associated with the LPCB and LPD, which means if communication within the organization is strong it will lead toward low psychological contract breach and power distance between the higher authority and subordinates is lower they frequently communicate their problems and give suggestion. As discussed, PC and communication have very strong relationship; communication improves the trust among the employees toward the organization which lead toward committed, motivated workforce. It is proved that once the chain of communication is broken it is hard to repair again the same status in the mind of employees.

Table1: Reliability Statistics

\begin{tabular}{llll}
\hline S.N & Factors & Cronbach's Alpha & No of items \\
\hline 1 & EC & .961 & 18 \\
2 & PCB & .947 & 12 \\
3 & PD & .939 & 10 \\
\hline
\end{tabular}

By looking at the above table of reliability statistics, the value of cronbach's alpha .961 of effective communication shows the internal consistency of the scale. The Bambacas and Patrickson 2008 scale used in this analysis that consists of 18 items. The value indicates the good correlation among the items used in the scale. The good value of cronbach's alpha shows the scale is free from error term. Now look at the value of cronbach's alpha for psychological contract breach .947 which is good enough to predict the reliability of scale of (Robinson, 1996), (Robinson, 1997) and (Robinson \& Morrison, 2000) used in the questionnaire. The scale comprises of 12 items. The value of cronbach's alpha for power distance .939 shows the good correlation among items used in the scale of (Bochner \& Hesketh, 1994) \& (Cynthia Lee1, 2000). The total numbers of items used in this scale are 10.

Table2: Effective Communication - Rotated Component Matrix

\begin{tabular}{|c|c|c|c|}
\hline Questions & F1 & F2 & F3 \\
\hline Clarity of ideas and facts communicated to you in written & 0.91 & & \\
\hline Effective implementation of creative organizational vision and values & & & 0.74 \\
\hline Frequent communication in between you're your higher bosses & 0.59 & & \\
\hline Roles, rights, and responsibilities are properly communicated to employees & & 0.77 & \\
\hline You find it respectable and confident for organizational consideration to you & & & 0.88 \\
\hline Management is good at identifying the problems by itself (resolving conflicts) & & & 0.65 \\
\hline Management keep you informed and up-to-date & 0.53 & & \\
\hline Demonstration of well-organized and timely approachable goals & 0.66 & & \\
\hline Direction and goals are communicated to all employees regardless of position & & & 0.625 \\
\hline You find an empathetic (kind) work environment (empowerment) & & & 0.50 \\
\hline Your supervisor listens you properly & & 0.59 & \\
\hline Virtual communication tools are used in between you and organization & & 0.89 & \\
\hline Communication of job-related issues to employees that affect them & & 0.91 & \\
\hline Information sharing is promoted at all levels of organization & & 0.63 & \\
\hline You are always informed about meetings and sessions & 0.60 & & \\
\hline Word of mouth communication is optimistic at all & & 0.50 & \\
\hline You find here being proactive and taking initiatives & 0.66 & & \\
\hline Very good backup for emergency based communication to seniors & 0.91 & & \\
\hline
\end{tabular}

F1: Participative Communication

F2: Formal Communication

F3: Value Communication

Factor analysis has been done on each scale separately. The Eigen value of the software identifies the other factors in different scales. Researcher identified effective communication as a single factor while software perceives other three factors lying in the scale of effective communication these are named as participative communication, formal communication and value communication. 
Whereas; in the case of factor analysis of PCB scale, researcher consider it as one factor and software also identify this as a single factor. In the factor analysis of the power distance, researcher considers it a single factor and software perceive the two factors contribute to PD named low power distance and high power distance.

Table3: Model Summary

\begin{tabular}{lllll}
\hline Model & R & R square & Adjusted R square & Std. Error of the estimate \\
\hline 1 & $.997^{\mathrm{a}}$ & .993 & .993 & .083 \\
\hline
\end{tabular}

Table 4: Analysis of Variance (ANOVA) Results

\begin{tabular}{|c|c|c|c|c|c|c|}
\hline Model & & Sum of Squares & df & Mean Square & $\mathbf{F}$ & Sig. \\
\hline \multirow[t]{3}{*}{1} & Regression & 204.595 & 5 & 40.919 & $\begin{array}{l}5855.32 \\
9\end{array}$ & $.000^{\mathrm{a}}$ \\
\hline & Residual & 1.405 & 201 & .007 & & \\
\hline & Total & 206.000 & 206 & & & \\
\hline
\end{tabular}

Predictors: (Constant), High Power Distance, Low Power Distance, Value Communication,

Participative Communication, Formal Communication

Dependent Variable: Psychological Contract Breach

The value of adjusted R2 calculated as .993 which is too good to predict the dependent variable by keeping in view the position of adjusted R2 all the three independent variables namely participative communication, formal communication and value communication has significant contribution on the dependent variable. As, the significant value is .000 in the ANOVA table shows the overall fitness of the model.

Table 5: Standardized and Unstandardized Coefficients ${ }^{a}$

\begin{tabular}{|c|c|c|c|c|c|c|}
\hline Mod & & \multicolumn{2}{|c|}{ Unstandardized } & $\begin{array}{l}\text { Standardized } \\
\text { Coefficients } \\
\text { Beta }\end{array}$ & $\mathbf{t}$ & Sig. \\
\hline \multirow[t]{6}{*}{1} & (Constant) & .000 & .006 & & .000 & 1.000 \\
\hline & $\begin{array}{l}\text { Participative } \\
\text { Communication }\end{array}$ & .661 & .017 & .661 & 39.421 & .000 \\
\hline & Formal Communication & 638 & .026 & .638 & 24.827 & .000 \\
\hline & Value Communication & 655 & .013 & .655 & 48.858 & .000 \\
\hline & Low Power Distance & -.081 & .028 & -.081 & -2.882 & .004 \\
\hline & High Power Distance & -.122 & .018 & -.122 & -6.965 & .000 \\
\hline
\end{tabular}

a. Dependent Variable: Psychological Contract Breach

Participative communication, formal communication, value communication, low power distance and high power distance are positively and significantly related to psychological contract breach.

\section{Discussion}

The effective communication and its role in the organization for developing the psychological contract were found positive and significant in the community colleges. The research findings greatly support the argument of (Jacobs, 2006), that PC has highest relation with the communication. A good communication leads toward the LPCB which creates the trust and commitment in the mind of the employee about their organization. The $\mathrm{H} 1$ and $\mathrm{H} 2$ prove to be true after analysis. Empirically, it supports the (Thomson \& Hecker's, 2001) arguments that effective communication leads toward the LPCB and if within the organization communication is not strong the chances of the PBC are higher. The organization believes in the good employee and employer relations needs to make strong communication system. Effective communication system motivates the employees. PC help the management to develop the relationship with employees (Hiltrop, 1996) especially when the PC is developed and maintained the organization find more committed employee and violation of the PC results in the changing behavior of the employees (Hiltrop, 1996). The findings of the research suggest that PD play a mediating role between communication and PCB, countries with higher power distance have even more PCB e.g. Pakistan and countries with lower power distance have relatively low PCB e.g. 
Netherlands because lower power distance will give the motivated, satisfied and committed employee (Madlock, 2014). A comparative study by (Syed et al., 2015) shows that PCB is much larger in Pakistan than the Netherlands this is because the collectivists would have a higher threshold for the perception of breach compared to individualists.

The results further implies that when employees feel comfortable at work and they are communicated properly the chances of PCB will be lower and if employees feel discomfort in the organizational setting though the communication is effective the PCB will be higher (Bambacas \& Patrickson, 2008). This study suggests that organization needs to make their communication strong for getting the motivated, committed and satisfied employees. For this, there is no need to use all types of communication but there is a need to make it more effective for LPCB. The promises organization make with their employees must be fulfilled because if this trust is broken will not be developed again in the mind of employees. In this way, the organization will lose the qualified workforce; therefore, organization needs to work on the effective communication and minimize the gap between employee and supervisors.

Scholarly Contributions: This study contributes to the psychological contract in several ways. First, it examines the communication as an antecedent of psychological contract breach, which is largely missing in the literature of PC (Morrison and Robinson, 1997). Second, exploring the antecedents of PCB outside the European context is a contribution to the field of psychological contract. Third, most of the studies based on cultural dimension individualism but we focused on power distance as a mediator between communication and PCB.

Managerial Implications: Since affective communication is an important predictor of PCB, employers can reduce the PCB by ensuring the communication between employees and employer is effective. This could also be a way to reduce the negative outcomes of PCB such as employee emotions, attitudes and behaviors, and responses including increased turnover (Maertz \& Griffeth, 2004), reduced organizational citizenship behaviors and in-role behaviors, and increased deviant behaviors (Kickul, Lester, \& Finkl, 2002). Therefore, managers could consider to reducing the power distance in this way psychological contract provides a useful framework to help establish an open process of communication and negotiation about the employment deal (Herriot \& Pemberton, 1997). This process could contribute considerably to reducing the incongruence between employee and management perceptions about communication.

Limitations and Directions for Future Research: The current study focused on understanding the communication as antecedents of psychological contract breach. PCB could also be understood by considering other relevant antecedents such as organizational cultural dimensions. In addition, future studies could be based on designing a country more diverse sample by considering other sectors, which will improve the generalizability of results.

\section{References}

Bambacas, M. \& Patrickson, M. (2008). Interpersonal communication skills that enhance organizational commitment. Journal of Communication Management, 12(01), 51-72.

Bhargava, U. A. (2013). Effect of psychological contract breach on the organizational outcome: Moderating role of tenure and education level. Vikalpa Volume 38.

Bochner, S. \& Hesketh, B. (1994). Power distance, individualism/collectivism, and job-related attitudes in a culturally diverse. Journal of Cross-Cultural Psychology, 3, 233-257.

Clutterbuck, D. (2005). Communication and the psychological contract. Journal of Communication Management, 09(04), 359 - 364.

Coyle-Shapiro, J. A. M. \& Conwey, N. (2006). Exchange Relationships: Examining Psychological Contracts and Perceived Organizational Support. Journal of Applied Psychology, 90(04), 774-781.

Cynthia Lee1, M. P. (2000). Power-Distance, Gender and Organizational Justice. Journal of Management, 6, 685-704.

David, C. \& Thomas, k. A. (2003). Cultural variation and psychological contract. Journal of organizational behavior, 3, 451- 471.

Dessler, G. (2013). Human Resource Management. In G. Dessler, Human Resource Management (13th ed., pp. 229). United States of America: Pearson Education, Inc., publishing as Prentice Hall. 
Guest, D. E. (2004). The Psychology of the Employment Relationship: An Analysis Based on the Psychological Contract. Applied psychology: an international review, 53(4), 541-555.

Guest, D. E. \& Conway, N. (2002). Communicating the Psychological Contract: An Employer Perspective. Human Resource Management Journal, 12(02), 22-38.

Guest, D. E. (1998). Is the psychological contract worth taking seriously? Journal of Organizational Behavior, $19,649-664$

Guzzo, R. A. \& Noonan, K. A. (1994). Human Resource Practices as Communications and the Psychological Contract. Human Resource Management, 33(03), 447-462.

Herriot, P. \& Pemberton, C. (1997). Facilitating new deals. Human Resource Management Journal, 7(1), 45-56.

Hiltrop, J. M. (1996). Managing the changing psychological contract. Employee Relations, 18(01), 36 - 49.

Hofstede, G. (1973-78). Motivation, Leadership, and Organization: Do American Theories Apply Abroad? European Institute for Advanced Studies in Management.

Hofstede, G. \& Bond, M. H. (1984). Hofstede's Culture Dimensions An Independent Validation Using Rokeach's Value Survey. Journal of cross-cultural psychology, 15(4), 417-433.

Jacobs, G. (2006). Communication for commitment in remote technical workforces. Journal of Communication Management, 10(04), 353 - 370.

Kickul, J., Lester, S. W. \& Finkl, J. (2002). Promise breaking during radical organizational change: Do justice interventions make a difference? Journal of Organizational Behavior, 23(4), 469-488.

Khan, D. S. (2008-2009). Public Administration with special reference to Pakistan. Amjad malik.

Latif, M. S. (2015). Hofstede Dimensions of Culture A Brief Comparison between Pakistan and New Zealand. Academy of Contemporary Research Journal, 2, 22-26.

Maertz Jr, C. P. \& Griffeth, R. W. (2004). Eight motivational forces and voluntary turnover: A theoretical synthesis with implications for research. Journal of Management, 30(5), 667-683.

Madlock, P. E. (2014). The Influence of Power Distance and Communication on Mexican Workers. International journal of business communication (IJBC), 2(3).

Morrison, E. W. \& Robinson, S. L. (1997). When employees feel betrayed: a model of how psychological contract violation develops. Academy of Management Review, 22(1), 226-56.

Moore, B. (2006). India thinks. Retrieved from India think: http://indiathink.com/power-distance/

Robinson, S. L. (1996). Trust and Breach of the Psychological Contract. Administrative Science Quarterly, 2, 574-599.

Robinson, E. W. (1997). When Employeesf Eelb Etrayeda: Modelo F How Psychological Contract Violation Develops. Academy of Management Review, 2, 226-256.

Robinson, S. L. \& Morrison, E. W. (2000). The development of psychological contract breach and violation: a longitudinal study. Journal of Organizational Behavior, 21(5), 525-46.

Sparrow, P. R. \& Cooper, C. L. (2003). The Psychological Contract. In P. R. Sparrow, \& C. L. Cooper, The Employment Relationship Key challenges for HR (pp. 41-65). Butterworth-Heinemann, An imprint of Elsevier, Linacre House, Jordan Hill, Oxford.

Syed, S., Arain, G. A., Schalk, R. \& Freese, C. (2015). Balancing Work and Family Obligations in Pakistan and the Netherlands: A Comparative Study. Global Business and Organizational Excellence, 34(5), 39-52.

Thomson, K. \& Hecker, L. (2001). Value-adding communication: Innovation in employee communication and internal marketing. Journal of Communication Management, 05(01), 48-58.

Turnley, W. H. \& Feldman, D. C. (1999). The impact of psychological contract violations on exit, voice, loyalty, and neglect. Human Relations, 52(7), 895-922.

Wanous, J. P., Poland, T. D., Premack, S. L. \& Davis, K. S. (1992). The effects of met expectations on newcomer attitudes and behaviors: a review and meta-analysis. Journal of Applied Psychology, 77(3), 288-97. 